\title{
A STUDY OF SOCIAL SKILLS OF SPECIAL CHILDREN
}

\author{
APARNA MATHUR ${ }^{1} \&$ S.K. MAHTO ${ }^{2}$ \\ ${ }^{1}$ Research Scholar, Sunrise University, Alwar, Rajasthan, India \\ ${ }^{2}$ Supervisor, Sunrise University, Alwar, Rajasthan, India
}

\begin{abstract}
The primary concept of the paper is to analyse the literature that is accompanied by the social skills training for those students who faces difficulties in dealing in general as well as the special situation in an educational environment. Research presented with this review was based on the data that is derived from the research papers, books, and the reports which were published.

KEYWORDS: Social Skills, Special Children
\end{abstract}

Received: Jun 01, 2020; Accepted: Jun 20, 2020; Published: Jun 30, 2020; Paper Id.: IJMPERDJUN2020138

\section{INTRODUCTION}

This particular paper com reviews the social abilities of students along with the problems related to emotional issues. The objective of this paper is to analyse the literature which was published that are related to the social skills training for the students along with the difficulties that they face in social situations. Studies are thoroughly analysed to review the efficiency of the different social skills training (SST) approaches and procedures. Another principle related to this paper is to figure out the trends in the SST that occurred during the last 30 years.

Social skills are very important in order to interact with people, acclimatize, and work well within the social environment. Additionally, when we are able to communicate efficiently with people is a crucial aspect of various experiences that will flourish the life like participating in various recreational activities, building friendship, or be a part of different groups. Having said that, for kids and youngster with E/BD, problems with the interpersonal relationship are not a far-fetched concept. As a matter of fact, having issues with social interactions is generally the main character when people are diagnosed with these problems. Although, because of the extensive focus on academics, socials skills training and development is not considered a common curriculum component.

As per Rohindekar and Usha (1988), social skills are considered as socially renowned learned training that allows the people to communicate in different acceptable ways that produce confident and constructive aids in circumventing the negative results from social issues. They are some particular strategy that is used by people to do various social tasks with maximum efficiency and hence is considered as socially skilled. Social skills are made of competencies that are necessary for the students to set off and maintain positive and strong social relationship with teachers, peers, family, and other members of the community (Alur, 2002).

\section{LITERATURE REVIEW}

The main discoveries that are presented in the report were basically the research results of a very important review $\mathrm{f}$ the literature that is connected with the training of social skills for the students facing different behavioural issues. 
The discoveries of research were based on data that were accumulated from research papers, books, and reports that were published from the year 1970s to 2004 in the USA. Wilson Select Plus, Academic Search Premier, and ERIC were some database analysed by descriptors social skills intervention, social skills training, social skills and emotional/behavioural disorders, social skills valuation.

Selected articles are data which are based on either qualitative or quantitative design. Although, dissertations and Non-English articles are not a part of this. Currently, there are different approaches being used to improve the social competence of the students and further explore their issues based on the execution of the social skills curricula that are being identified and explained. The main intention of the author is to identify and observe the current practices and make comment on their effectiveness and versatility.

Social skills training: As it is mentioned above a significant and thorough research has been performed to figure out the efficiency of the social skills interference. During the late 1970s, the concept of SST emerged as an effective approach to teaching social skills to the students who are diagnosed with social issues in the community (Rutter and Yule, 1975).

The 80s decade saw various educators (Mohapatra, 2004) for the schools to generate more systematic and formal procedure to teach social skills to the students along with both performance and skill discrepancies. Muscott (1988) considerably supported social skills intervention and a key element of the programs that help the students reintegrate along with special requirements into fewer programs of restrictive placements in the educational settings.

Cooperative learning groups recollect the efficiency of the universal training or whole-group, on the other hand, improving the individualization and effectiveness of the specific group training. Additionally, cooperation approaches set of instructions of social skills in a deliberate and sequential manner. Instead of particular teaching social skills that are focused on the lesson of the current time, with an assumption that students will get these skills because of the side effect of the group process, the simple and normal cooperation models accompanies with specific social skills which are a part of the curriculum. Cooperatives learning organizations have been seen to be a great environment for educating the students about social skills (Paranjpe, 1996). It turns out to be an effective method to encourage and maintain a sense of community in the classroom while providing and teaching positive peer interaction in a setting that is beneficial for an individual as well as others.

\section{PEER MEDITATIONS AND CONFLICT RESOLUTION}

Peer mediated technique, a particular peer without having any disabilities are educated and trained by an adult to communicate effectively with a student that deals with social disabilities (Mohite, 1994). In this following training procedure, both the students meet for pre-decided social activities along with the trained peer models educates and promotes social behaviour and responses from the targeted student. Peer-mediated methods make sure that there is no intervention of the adult, which increases the probability that the students will the community and not just reply to the promoter, in a setting encouraging to evolving interaction that is also age-appropriate.

Peer meditation identifies that the students are capable of performing conflict resolution practices as well as social skills in order to enact a leadership role in promoting peace and decreasing the peer violence in the schools (Rohindekar and Usha, 1988). Using peers stimulates the positive behaviour that seems as naturally rewarded, promote the chances that show the positive behavioural changes will stay with the student and can be easily used in different social situations. 


\section{COGNITIVE-BEHAVIOURAL INTERPERSONAL PROBLEM-SOLVING}

Cognitive-behavioral interpersonal problem-solving is a procedure that is specifically designed to improve the overt behavioral change by educating children to change the thought processes and teaching the particular prosaically skills that are necessary for social media communications (Alur, 2002). As the name suggests, these said programs feature a set of the strategic approach that is specifically designed to educate the children about the process related to how to think with a specific skill approach to educate them about the necessary behave to uplift their social interactions. By using the cognitive problem-solving skills like creating effective solutions to different social problems and generating mean-ends thinking by putting together different behavioral training strategies like modelling, role playing, self-control strategies, corrective feedback, and positive social enforcement. Researchers have shown that a person's capability to deal with the different social problem is effectively increased with social meta-cognitive skills that allow the individual to figure out the variables that help in differentiating the requirements of response (Paranjpe, 1996).

\section{ANGER MANAGEMENT}

The coping with the ability of an individual like anger management is basically the abilities to concentrate on problems as well as the things that trigger these problems. Children who are anxious, hungry, or have IQ are more likely to lose their anger (Rutter and Yule, 1975). The education provided to children about the positive self-talk, various techniques to solve the problems. There are certain skills that are required for anger management which comprises of self-awareness of anger and its signal, non-antagonistic ability to respond utilization of individual excitement motions as prompts to utilize nonopposing systems, view of poise over circumstance, and self-guideline strategies to manage each phase of incitement, and keeping up high confidence (Mohite, 1994). Guide direction with social fortification to support has additionally been persistently used to help understudies to oversee outrage (Alur, 2002).

\section{SELF-CONTROL STRATEGIES}

Self-control is an effective and powerful device and is not subject to a custom curriculum educator or being in an uncommon setting. Simplifications of self-control techniques that are made strong without any monitoring from the outside, self-assessment, and self-support can be utilized as a supplement to teacher-mediated behaviour management approaches in the classroom (Rohindekar and Usha, 1988).

Below are the three stages that these researchers pointed out.

- Self-monitoring. Self-monitoring should be focused on when the behaviour targeting the anger is clearly identified. (For eg., self-monitoring for growing on-task behaviour when working on an individual work)

- Self-evaluation. Students get to compare and evaluate their behaviour to the pre-determined standards and give out a quality and acceptable judgment.

- Self-reinforcement: procedures to take up self-control strategies is to include important target behaviour, offer a foundation for the self-control, develop a system for self-control, give direct and clear instruction, offer generalization program, constantly monitor the accuracy, and valuate the considerations. 


\section{CURRICULUM-BASED INTERVENTION}

Various author advices the combining of social abilities training into the standard educational programs. The learning of social aptitudes, emotional segregation, and critical thinking has been effectively incorporated into the literature (Sharma, 1997). Utilizing children's literature has been observed to be compelling in enhancing the comfort level of friendship abilities in young kids dealing with learning inabilities (DE George, 1998). A portion of the scenes from Shakespeare's Romeo and Juliet loan themselves to dialogs of social abilities, critical thinking, and contrasting options to animosity (Rohindekar and Usha, 1988).

Social skill literature strategy (SSLS) programs offer a model to incorporating social and ability development in the education modules of elementary and middle school language arts curriculum (Mohite, 1994). Teachers can utilize stories and systems in order to give life to literature. The story approach educates and encourages the students to investigate struggle, talk about character, acknowledge assorted variety, useperusing techniques and increment understanding. Literature brings together the world that is just in writing to the students own particular lives and the relationship with the outside world.

With the help of the stories, students can create effective critical thinking abilities, discover the meaning of being moral, and address issues, for example, viciousness, separation, tormenting and badgering (Alur, 2002). The SSLS demonstrate is versatile to an assortment of learning conditions and is effectively put in any dialect expressions program since teachers deal with the literature they are already teaching their students (Paranjpe, 1996). History and social studies likewise give chances to learning of social practices.

- Empathy- observing the situations and identifying the feeling your oneself as well as others;

- Cue sensitivity- stimulating the knowledge of verbal, nonverbal and setting's signals;

- Alternative thinking- interpreting different view point and solutions to social issues;

- Consequential thinking- the knowledge to foresee the coming consequences;

- Implementation of skills- observing, identifying, implementing, and monitoring the most effective solution, and

- Integration- observing and utilizing the skills related to problem solving in both hypothetical as well as real life situations. The teachers can alter the objectives as they incorporate the activities in their social skill teaching.

\section{CONCLUSIONS}

In the course of three decades, an assortment of social aptitudes programs has been produced to help the teachers with the complicated task of showing kids and teenagers prosaically, relational practices. These projects are driven by various fundamental hypothetical introductions that by and large can be categorized as one of four classes: full of feeling, behavioral, intellectual and multidimensional (Rutter and Yule, 1975). The literature has set up that there is a requirement for some mediation to enhance the social and relational practices of the students with E/BD. Generally, SST has been appeared to be powerful in enhancing the social practices of the students with $\mathrm{E} / \mathrm{BD}$ at certain timeframe and in a predetermined number of settings. There are plenty of hypothetical and exact literature on showing social aptitudes to the students recommending that social abilities guideline includes the deliberate and structured presentation of materials and direct direction of the objective aptitudes. A nearby examination of the writing about SST educational programs 
additionally demonstrates that (an) immediate instructing of social abilities creates constructive socially acknowledged examples of conduct and add to the improvement of constructive connections and help with maintaining a strategic distance from contrary social capabilities; (b) the immediate educating of social aptitudes can be a viable intercession; (c) relational or social abilities meditation effectively affect an extensive variety of measured results which incorporate increment of scholarly achievement in school and also positive associations with family, companions, and grown-ups. These results lead students with E/BD to end up noticeably more socially adequate in school and the general public. Meanwhile, it is additionally critical to take note of that students with E/BD ordinarily learn in a non-conventional way, and it is impossible that they will consequently or normally secure depending on abilities in a proportionate way with their companions without E/BD.

The present survey of the literature likewise uncovers that in spite of a very long while of speculating, working on, debating, and inquiring about, the instructive group has not possessed the capacity to touch base under the most favourable conditions rehearse demonstrate for the recognizable proof, estimation, preparing, speculation, and upkeep of social aptitudes for understudies with E/BD. Inability to touch base at the perfect preparing program has come about because of the absence of agreement among analysts and specialists with respect to many issues, for example, the meaning of terms, testing and preparing systems. Likewise, the distinguishing proof of which particular abilities to focus in preparing is frequently subjective, and attitudes are generally chosen with no exact legitimization of their need of recognized understudies (Mohapatra, 2004). Further, strategies utilized as a part of training, for example, displaying and instructing are regularly chosen self-assertively, with little individualization in light of the idea of understudies' execution or aptitude shortfalls (Sharma, 1997). At last, experts concur that dreadfully numerous economically accessible SST programs have been distributed without recorded observational proof of their adequacy.

\section{REFERENCES}

1. Alur, M. (2002). "Special Needs Policy in India", in S. Hegarty and M. Alue (eds), Education and Children with Special Needs: From Segregation to Inclusion. New Delhi: Sage.

2. Mohapatra, C. S. (2004). Disability Management in India: Challenges \& Commitments. New Delhi: National Institute for the Mentally Handicapped (NIMH) and the Indian Institute of Public Administration.

3. Mohite, P. (1994). Working with Disabled Children: Curriculum and Assessment. Independent Study. Baroda: The Maharaja Sayaji Rao University of Baroda.

4. Paranjpe, S., (1996). "Achievement of Normal and Hearing Handicapped Pupils at the End of the Primary Cycle”, Disabilities and Impairments -, 19(2): 73-86.

5. Rohindekar, S.R. and Usha, M.N. (1988). Educational and Vocational Needs of Physically Handicapped Children. Bangalore: Institute for Social and Economic Change.

6. Rutter. M. and W. Yule (1975). "The Concept of Specific Reading Retardation”, Journal of Child Psychology and Psychiatry, 16: 181-97.

7. Sharma, P. L. (1997). "Education of Children with Hearing Impairment”, The Primary Teacher 12 (1): $26-29$.

8. Rani, Poonam and Bimla Dhanda. "The Influence of Caste Soft Skills and Social Skills Development among Children." International Journal of Business and General Management (IJBGM) 7.3 (2018):95-98 
9. Saini, Varsha, and Bimla Dhanda. "A Complementary Relationship between Communication Skills and Social Skills among Rural Children." International Journal of Humanities and Social Sciences (IJHSS) 6.2 (2017):11-16

10. Danquah, Emelia., and Theophilus B. Wireko. "The impact of each element of emotional intelligence on customer service delivery: A customer satisfaction perspective." International Journal of Sales \& Marketing Management Research and Development (IJSMMRD) 4.2 (2014): 9-20.

11. Banu, A. Anis Akthar Sulthana. "To Study the Influence of Emotional Intelligence on Women Executives in Private Sector Enterprises." International Journal of Human Resource Management and Research (IJHRMR) 5.1 (2015):11-20

12. Sarma, Moyuri. "Environmental Education for Sustainable Development: A Study Conducted in the Schools of Greater Guwahati, Assam." International Journal of Civil, Structural, Environmental and Infrastructure Engineering Research and Development (IJCSEIERD) 7.4 (2017):9-14

13. Prabakaran, M. "Information Literacy: Essential Skill for Higher Education." International Journal of Humanities and Social Sciences (IJHSS) 5.4 (2016):27-32

14. Mahmood, Azhar, and Irfan Ashraf. "Peace Education: Conceptual awareness of Teachers at Elementary School Level." International Journal of Educational Science and Research (IJESR) 4.2 (2014): 15-20. 